\title{
Molecular Analysis of a Novel Glutamine Synthetase of the Anaerobe Bacteroides fragilis
}

\author{
By RUSSELL T. HILL, JOAN R. PARKER, HEIDE J. K. GOODMAN, \\ DAVID T. JONES $†$ AND DAVID R. WOODS* \\ Department of Microbiology, University of Cape Town, Rondebosch 7700, South Africa
}

(Received 19 June 1989; revised 31 August 1989; accepted 18 September 1989)

\begin{abstract}
The nucleotide sequence of a 2777 bp DNA segment containing the Bacteroides fragilis glnA gene was determined. The $B$. fragilis $g \ln A$ open reading frame of $2187 \mathrm{bp}$ encoded a glutamine synthetase (GS) subunit of 729 amino acid residues with a calculated $M_{\mathrm{r}}$ of 82827 . The apparent $M_{\mathrm{r}}$ of the GS subunit determined by SDS-PAGE was approximately 75000 . A single mRNA transcription start point was identified upstream of the $B$. fragilis $g \ln A$ open reading frame. The $B$. fragilis GS subunit is approximately 270 and 400 amino acids longer than the GSI and GSII subunits, respectively, of other prokaryotes and eukaryotes. The GSI and GSII holoenzymes are dodecamers and octamers respectively, whereas the GS of $B$. fragilis is a hexamer. Although GSI and GSII subunits show amino acid similarity in five conserved regions, this similarity is not strongly conserved in the $B$. fragilis GS. The GS of $B$. fragilis is not regulated by adenylylation and lacks the adenylylation site. It also lacks the Trp residue associated with the active site in GSI and GSII enzymes from other prokaryotes and eukaryotes.
\end{abstract}

\section{INTRODUCTION}

Glutamine synthetase (GS) (EC 6.3.1.2) is an important enzyme in nitrogen metabolism and ammonia assimilation in many prokaryotes, eukaryotes and archaeobacteria. GS enzymes of eukaryotic origin are octamers (Prusiner \& Stadtman, 1973) whereas the GS enzymes of eubacteria and an archaeobacterium are dodecamers of $M_{\mathrm{r}}$ approximately 600000 composed of a single type of subunit, the $M_{\mathrm{r}}$ of which falls in the range 44000 to 59000 (Streicher \& Tyler, 1980; Bhatnagar et al., 1986).

Prokaryotes have two forms of GS, termed GSI and GSII. The majority of bacteria investigated have GSI enzymes but members of the Rhizobiaceae contain both GSI and GSII enzymes. GSI is the typical prokaryotic GS whereas GSII is similar to eukaryotic GS enzymes (Carlson \& Chelm, 1986). Prokaryotic GSI subunits investigated vary in length from 444 to 474 amino acids (Janssen et al., 1988), whereas the GSII subunits of eukaryotes investigated vary in length from 355 to 373 amino acids (Gebhardt et al., 1986; Hayward et al., 1986; Tischer et al., 1986). The eukaryotic GSII subunits lack the C-terminal portion of the prokaryotic GSI subunit including the adenylylation site. The GSII subunit from Bradyrhizobium japonicum is 329 amino acids long and also lacks the terminal portion of the GSI subunit and the adenylylation site (Carlson \& Chelm, 1986). In a comparison of prokaryotic and eukaryotic GSI and GSII enzymes, Rawlings et al. (1987) showed that although the amino acid similarity between the enzymes was only approximately $15 \%$, the major part of this similarity was located in five

† Present address: Department of Microbiology, University of Otago, Dunedin, New Zealand.

Abbreviations: $g \ln A$, gene encoding glutamine synthetase; GS, glutamine synthetase; ORF, open reading frame; SD, Shine-Dalgarno.

The nucleotide sequence data reported in this paper have been submitted to GenBank and have been assigned the accession number M28252. 
regions corresponding to $\beta$-sheets in the Salmonella typhimurium enzyme (Almassy et al., 1986). These regions are strongly conserved in all GS enzymes analysed to date (Janssen et al., 1988). A feature of the five conserved amino acid regions is that they are all associated with the proposed GS active site (Almassy et al., 1986; Janson et al., 1986). Regions II to V are $\beta$-strands closely associated with two $\mathrm{Mn}^{2+}$ cations of one subunit, while region I contains the Trp residue which is thought to complete the active site formed between adjacent subunits.

An indication that the GS from the Gram-negative obligately anaerobic bacterium Bacteroides fragilis may differ from other GS enzymes of eukaryotes and prokaryotes was suggested by Southern et al. (1986, 1987). Studies of the cloned B. fragilis GS subunit produced in Escherichia coli and $B$. fragilis indicated that the $B$. fragilis GS subunit was substantially larger ( $M_{\mathrm{r}}$ approximately 75000 ) than other GSI and GSII subunits (maximum $M_{\mathrm{r}}$ approximately 59000). However, the $M_{\mathrm{r}}$ of the $B$. fragilis GS holoenzyme (approximately 490000) was lower than that of the prokaryotic GSII holoenzyme (approximately 600000). It was concluded that the GS of this anaerobic prokaryote is a hexamer and not a dodecamer. To confirm the structure of the $B$. fragilis GS we sequenced the $g \ln A$ gene and compared the nucleotide sequence and the derived amino acid sequence with other GSI and GSII enzymes. We report that the GS from $B$. fragilis differs markedly from the GSI and GSII enzymes from other prokaryotes and eukaryotes.

\section{METHODS}

Bacterial strains, plasmids and growth conditions. B. fragilis strain Bf-1 was described by Mossie et al. (1979) and was used by Southern et al. $(1986,1987)$ for the cloning of the $B$. fragilis $g \ln A$ gene. Plasmid pJS139 [GlnA ${ }^{+}$, ampicillin resistant $\left.\left(\mathrm{Ap}^{r}\right)\right]$, is an $E$. coli recombinant plasmid which contains the $B$. fragilis $\mathrm{Bf}-1 \operatorname{gln} A$ gene and enables $E$. coli gln $A$ deletion mutants to utilize $\left(\mathrm{NH}_{4}\right)_{2} \mathrm{SO}_{4}$ as a sole source of nitrogen (Southern et al., 1986, 1987). E. coli strains were grown on Luria medium (Miller, 1972) or glucose minimal medium (Miller, 1972) with $1 \mathrm{~g}$ $\left(\mathrm{NH}_{4}\right)_{2} \mathrm{SO}_{4}$ per litre as the sole nitrogen source. All strains were grown at $37^{\circ} \mathrm{C}$ with aeration.

Preparation of DNA. Plasmid DNA was prepared by the alkali-hydrolysis method of Ish-Horowicz \& Burke (1981).

DNA sequence analysis. DNA sequencing of both strands of plasmids containing the cloned $B$. fragilis glnA gene was done by the dideoxynucleotide triphosphate chain termination method of Sanger $e t$ al. (1977) with templates prepared from DNA subcloned in pUC18 and pUC19 and exonuclease III digestion (Henikoff, 1984). E. coli LK111 (Zabeau \& Stanley, 1982) was used as the recipient strain. The DNA chains were radiolabelled with $\left[{ }^{35} \mathrm{~S}\right] \mathrm{dCTP}\left(400 \mathrm{Ci} \mathrm{mmol}^{-1} ; 14.8 \mathrm{TBq} \mathrm{mmol}{ }^{-1}\right)$. The DNA and deduced amino acid sequences were analysed with an IBM XT computer using a GENEPRO (version 3.1) program (Riverside Scientific).

Primer extension reactions. A synthetic 17-mer oligonucleotide 5'ATAGCTCTTGTAGTGCG-3' was used as a primer for the synthesis of cDNA. A [ $\left.\alpha^{-32} \mathrm{P}\right]-5^{\prime}$ end-labelled primer $(5 \mathrm{ng})$ was mixed with $10 \mu \mathrm{g}$ of RNA prepared from B. fragilis Bf-1 or E. coli LK111(pJS139) by the method of Aiba et al. (1981). The mixture was denatured at $95^{\circ} \mathrm{C}$ in $10 \mathrm{~mm}$-Tris/ $\mathrm{HCl} \mathrm{pH} \mathrm{8.3,} 0.35 \mathrm{~mm}$-EDTA for $5 \mathrm{~min}$ and chilled on dry ice. Primer-RNA hybridizations were incubated at $42{ }^{\circ} \mathrm{C}$ for $6 \mathrm{~h}$. The reverse transcription reaction was carried out at $42^{\circ} \mathrm{C}$ for $60 \mathrm{~min}$ in $20 \mu \mathrm{l}$ of $50 \mathrm{~mm}$-Tris $/ \mathrm{HCl}, \mathrm{pH} 8.3,8 \mathrm{~mm}-\mathrm{MgCl}_{2}, 2 \mathrm{~mm}$-DTT, $1 \mathrm{~mm}$ each of dGTP, dATP, dCTP, dTTP and 50 units of reverse transcriptase. The RNA was degraded with RNAase A $(20 \mu \mathrm{g})$ for $10 \mathrm{~min}$ at $37^{\circ} \mathrm{C}$. After phenol extraction and ethanol precipitation the cDNA was resuspended in $10 \mu \mathrm{l}$ of $99 \%(\mathrm{w} / \mathrm{v})$ formamide, $0.1 \mathrm{mg}$ bromophenol blue $\mathrm{ml}^{-1}, 0 \cdot 1 \mathrm{mg}$ xylene cyanol ml${ }^{-1}$ and electrophoresed in a sequencing gel.

\section{RESULTS AND DISCUSSION}

\section{Nucleotide sequence and transcription start point of $g \ln A$ gene}

The nucleotide sequence of a 2777 bp region of $B$. fragilis DNA containing the $g \ln A$ gene was determined. The DNA sequence contained an open reading frame (ORF), which from a start codon (ATG) to a stop codon contained 2187 nucleotides (Fig. 1). Primer extension experiments carried out with RNA isolated from $B$. fragilis cells grown in brain heart infusion broth

Fig. 1 (on facing page). Nucleotide sequence for the $g \ln A$ gene of $B$. fragilis with up- and downstream regions. The derived amino acid sequence is given in the one-letter code from positions 1 to 2187 ( 729 residues). The -10 and -35 regions of the putative promoter are in boldface type and underlined. The putative Shine-Dalgarno (SD) sequence AAAAGAGA starts at position - 8. Two near-perfect direct repeat sequences from positions -127 to -82 and -74 to -30 are marked with lines above the sequences. 


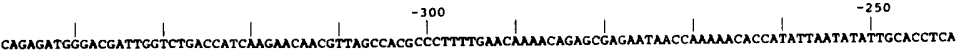

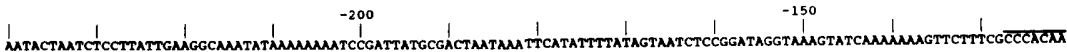

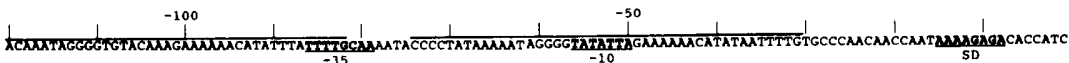

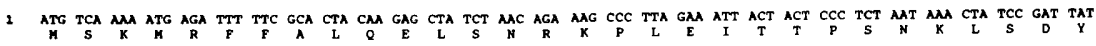

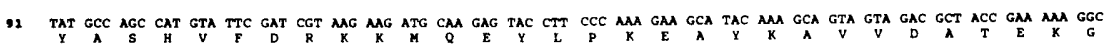

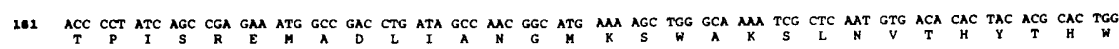

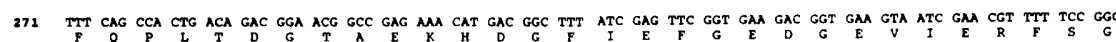

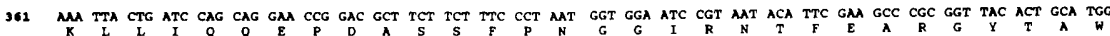

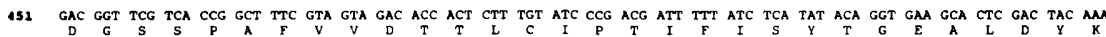

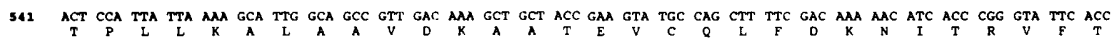

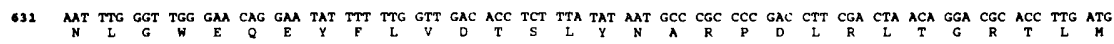

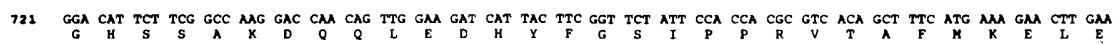

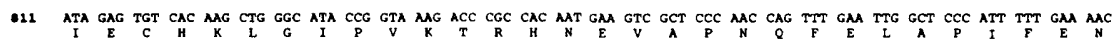

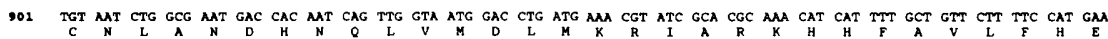

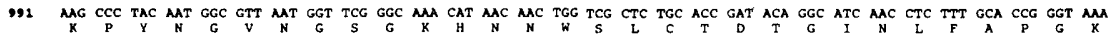

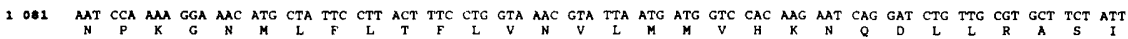

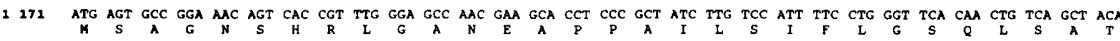

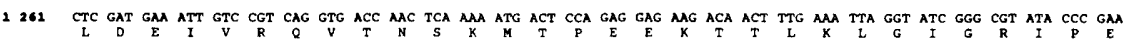

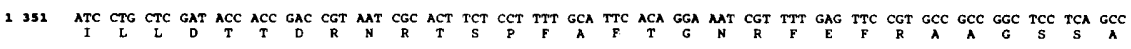

1412 AHC TGT GCT GCT GCC

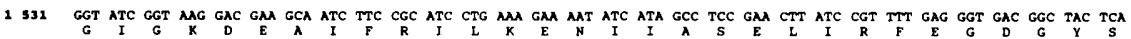

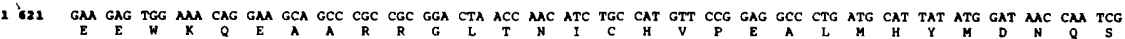

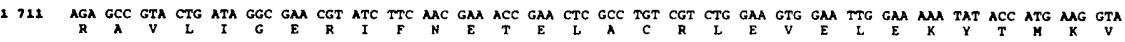

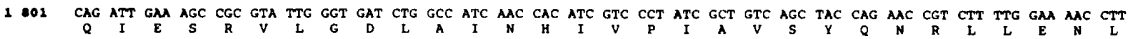

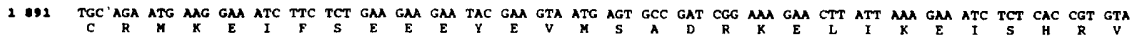

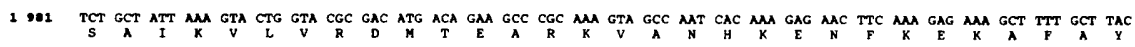

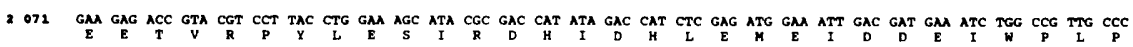

2101 NAA TAC AGA GAA CTG TTA TTC ACG AAG TMA GCCATACTTGATGTCTCCCCGTAAGMAGGTCCTTTTCAMAGATCTCTTATGGGGAGCTTTTCATTTCCGGGGTTTCCTC

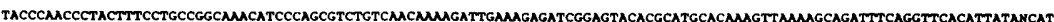
ATCCCACTGCTGTTCGCTCATACGCATCATCATCCGTCACG 


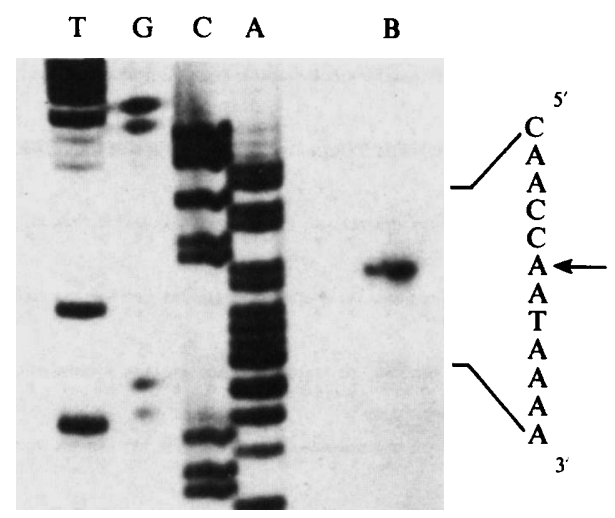

Fig. 2. Transcript mapping of $g \ln A$ in mRNA from $B$. fragilis (lane B). Lanes $A, C, G$ and $T$ represent the dideoxy sequencing reaction products of pJS139 DNA primed with the synthetic primer. The $5^{\prime}$ end of the $g \ln A$ transcript was determined by primer extension. The transcription start point is indicated with an arrow alongside the corresponding DNA sequence.

(Holdeman \& Moore, 1972) showed a single major transcription start point $18 \mathrm{bp}$ from the first nucleotide of the ATG start codon (position + 1) of the 2187 bp ORF (Fig. 2). Similar primer extension experiments carried out with RNA isolated from E. coli (pJS139) cells showed a number of weak transcription start points within 16 to $40 \mathrm{bp}$ of the ATG start codon (results not shown). Although promoter consensus sequences for $B$. fragilis have not been defined, it is interesting that an $E$. coli promoter sequence containing -10 and -35 RNA-polymerasebinding consensus sequences separated by $22 \mathrm{bp}$ is situated $32 \mathrm{bp}$ upstream of the $B$. fragilis transcription start point (Fig. 1). Previously we reported that the apparent $M_{\mathrm{r}}$ of the $B$. fragilis GS subunit determined by SDS-PAGE was approximately 75000 (Southern et al., 1986, 1987). The start region of the $B$. fragilis $g \ln A$ ORF contains five in-phase ATG start codons which would result in proteins with calculated $M_{\mathrm{r}}$ values of $82827,82481,78067,75131$ and 74345 respectively (Fig. 1). The next downstream in-phase ATG codon would produce a protein with a calculated $M_{\mathrm{r}}$ of 55823 , which is too small to be regarded as the $B$. fragilis GS. The first ATG codon is preceded by an AAGAGA sequence eight nucleotides from the presumptive start codon. This AG-rich region shows some similarity to other Shine-Dalgarno (SD) sequences (Shine \& Dalgarno, 1976) and is situated close enough to the start of the ORF to be regarded as a putative SD region. The other four ATG codons were not preceded by sequences which showed similarity to SD sequences. The $B$. fragilis $g \ln A$ gene was expressed in $E$, coli from a promoter site contained within the cloned $B$. fragilis DNA (Southern et al., 1986). Attempts to sequence the amino-terminal end of the GS subunit were unsuccessful as the protein appeared to be blocked. A feature of the upstream region is the presence of two near-perfect direct repeat sequences of 46 and 45 bp from positions -127 to -82 and -74 to -30 respectively (Fig. 1). This region of direct repeats overlaps the putative promoter sequence and may be involved in the regulation of GS expression. The regulation of the glnA gene in Salmonella typhimurium and $E$. coli involves five $\mathrm{NR}_{\mathrm{I}}$ binding consensus sequences of $15 \mathrm{bp}$ (Ames \& Nikaido, 1985). Some of the $\mathrm{NR}_{\mathrm{I}}$ binding sites overlap the $g \ln A$ promoters. However, there is no homology between the repeats upstream of the $B$. fragilis $g \ln A$ gene and the $\mathrm{NR}_{\mathrm{I}}$ binding consensus sequences.

\section{Comparison of $B$. fragilis $G S$ with other GS enzymes}

Recently Rawlings et al. (1987), Janssen et al. (1988), Strauch et al. (1988) and Wray \& Fisher (1988) have compared the nucleotide-sequence-derived GS amino acid sequences from diverse prokaryotes including Bradyrhizobium japonicum (Carlson \& Chelm, 1986), E. coli (Colombo \& Villafranca, 1986), Anabaena sp. strain 7120 (Tumer et al., 1983), Thiobacillus ferrooxidans (Rawlings et al., 1987), Salmonella typhimurium (Janson et al., 1986), Clostridium acetobutylicum 

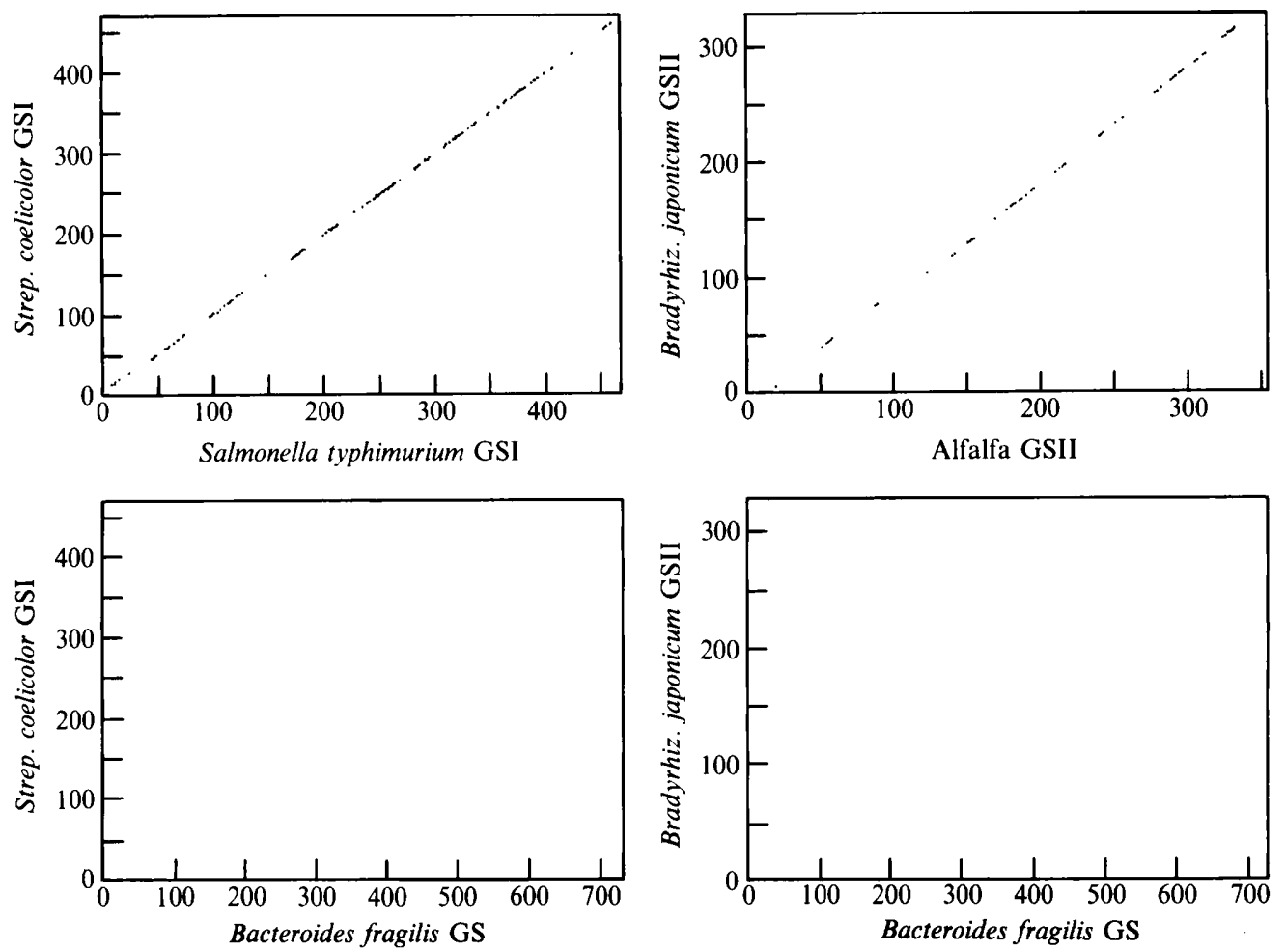

Fig. 3. Dot-matrix comparisons of amino acid sequences of GSI enzymes from Salmonella typhimurium and Streptomyces coelicolor, of GSII enzymes from alfalfa and Bradyrhizobium japonicum, and of the Bacteroides fragilis GS with a GSI enzyme and a GSII enzyme. Dot-matrix comparisons were done using the GENEPRO (version 3.1) sequence analysis program (Riverside Scientific), checking for five matches in a window of ten residues.

(Janssen et al., 1988), Bacillus subtilis (Strauch et al., 1988), Azospirillum brasilense (Bozouklian \& Elmerich, 1986) and Streptomyces coelicolor (Wray \& Fisher, 1988).

The GSII subunit from Bradyrhizobium japonicum contained 329 amino acids $\left(M_{\mathrm{r}} 36865\right)$, whereas the GSI subunits of the other bacteria contained 444 to 474 amino acids $\left(M_{\mathrm{r}} 49000\right.$ to 59000 ). In contrast, the Bacteroides fragilis $g$ In $A$ ORF of 2187 nucleotides encodes a GS subunit of 729 amino acid residues with a calculated $M_{\mathrm{r}}$ of 82827 . Thus the $B$. fragilis GS subunit is approximately 270 and 400 amino acids longer than the GSI and GSII subunits respectively. The calculated $M_{\mathrm{r}}$ of the $B$. fragilis GS confirms our previous results (Southern et al., 1987) involving PAGE analysis of the GS which indicated that the $B$. fragilis GS subunit was substantially larger than other prokaryote GS subunits.

The GSI and GSII enzymes can be separated into two groups on the basis of amino acid similarity. Although there is only limited amino acid similarity between these two groups, a high degree of similarity exists between GS enzymes within each group. This is illustrated by the dotmatrix comparisons of GS subunits from distantly related organisms within each group (Fig. 3). The GS from $B$. fragilis did not show any overall amino acid similarity with either GSI or GSII enzymes (Fig. 3).

The major regions of amino acid sequence similarity between the prokaryote GS enzymes involve five $\beta$-sheets which are all associated with the proposed GS active site (Almassy et al., 1986; Janson et al., 1986; Rawlings et al., 1987). These regions are also conserved in GS from eukaryotes (Janssen et al., 1988). A comparison of these five regions from representative groups of eukaryotes, prokaryotes and $B$. fragilis is shown in Fig. 4 . In the GS enzyme from $B$. fragilis 
$\begin{array}{ll}\text { REGION } \\ \text { HA } & 60 \\ \text { Af } & 54 \\ \text { Bf } & 12 \\ \text { An } & 50 \\ \text { Bt } & 49 \\ \text { Tf } & 50 \\ \text { CA } & 51 \\ \text { BC } & 48 \\ \text { Bg } & 51 \\ \text { Bf } & 149\end{array}$

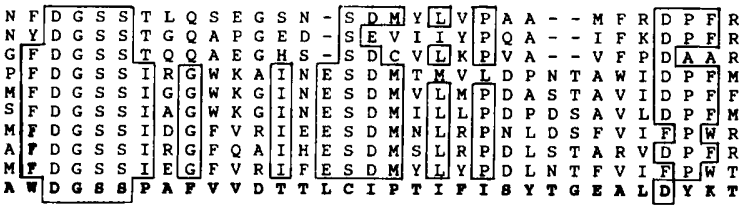

REGION II

$\begin{array}{ll}\text { He } & 195 \\ \text { Af } & 191 \\ \text { Bj } & 171 \\ \text { An } & 215 \\ \text { Bt } & 215 \\ \text { Tf } & 211 \\ \text { Ca } & 187 \\ \text { Be } & 212 \\ \text { Bs } & 188 \\ \text { Bf } & 285\end{array}$

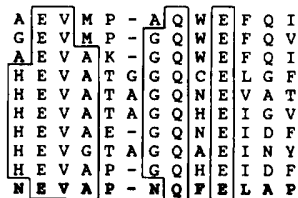

RRGTON ILI

$\begin{array}{ll}\text { HIA } & 237 \\ \text { Af } & 233 \\ \text { By } & 213 \\ \text { An } & 258 \\ 8 t & 255 \\ \text { If } & 253 \\ \text { CE } & 201 \\ \text { 8c } & 252 \\ \text { Bs } & 230 \\ \text { Bf } & 327\end{array}$

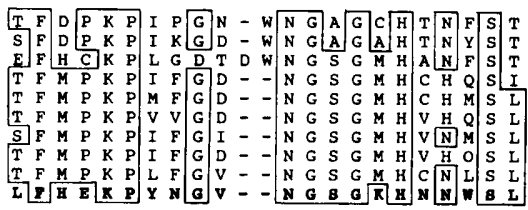

BEGIOY IV
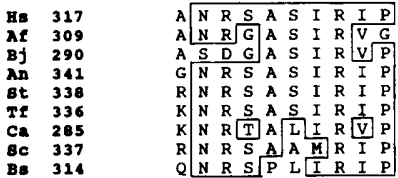

REGION $\mathbf{Y}$
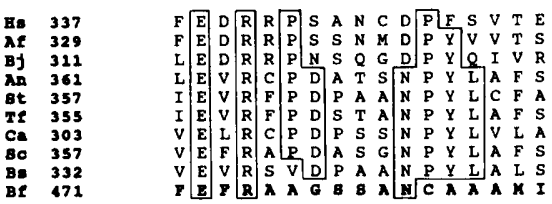

Fig. 4. Comparison of amino acid sequences of five regions of homology of GS enzymes from Homo sapiens (Hs) (Gibbs et al., 1987), alfalfa (Af) (Tischer et al., 1986), Bradyrhizobium japonicum (Bj) (Carlson \& Chelm, 1986), Anabaena sp. strain 7120 (An) (Tumer et al., 1983), Salmonella typhimurium (St) (Janson et al., 1986), Thiobacillus ferrooxidans (Tf) (Rawlings et al., 1987), Clostridium acetobutylicum (Ca) (Janssen et al., 1988), Streptomyces coelicolor (Sc) (Wray \& Fisher, 1988), Bacillus subtilis (Bs) (Strauch et al., 1988) and Bacteroides fragilis (Bf). The amino acids are identified by the single-letter code and the positions of the first amino acids in each region are indicated. Numbering of residues begins with the start methionine at the $\mathrm{N}$-terminal end. Identical residues are boxed. No region IV was found in $B$. fragilis.

these five regions show far less amino acid similarity although certain conserved amino acids can be identified in four of these five regions.

Region I of the $B$. fragilis GS shows recognizable but relatively poorly conserved amino acid similarity with the other GS enzymes (Fig. 4). The amino acid sequence DGSS at the start of region I is conserved in all the eukaryote and prokaryote GS enzymes. A Ser residue (the homologue of Ser-64 in Salmonella typhimurium) is conserved in all GS enzymes except in the $B$. fragilis GS, where it is replaced by a Cys residue (Cys-164 of $B$. fragilis).

In region I the $S$. typhimurium GS has a Trp residue at position 58 , which is thought to complete the active site formed between adjacent subunits (Almassy et al., 1986). In the GS from three Gram-positive bacteria, Bacillus subtilis, Clostridium acetobutylicum and Streptomyces coelicolor, the Trp residue is replaced by the functionally similar Phe residue. The Bacteroides 


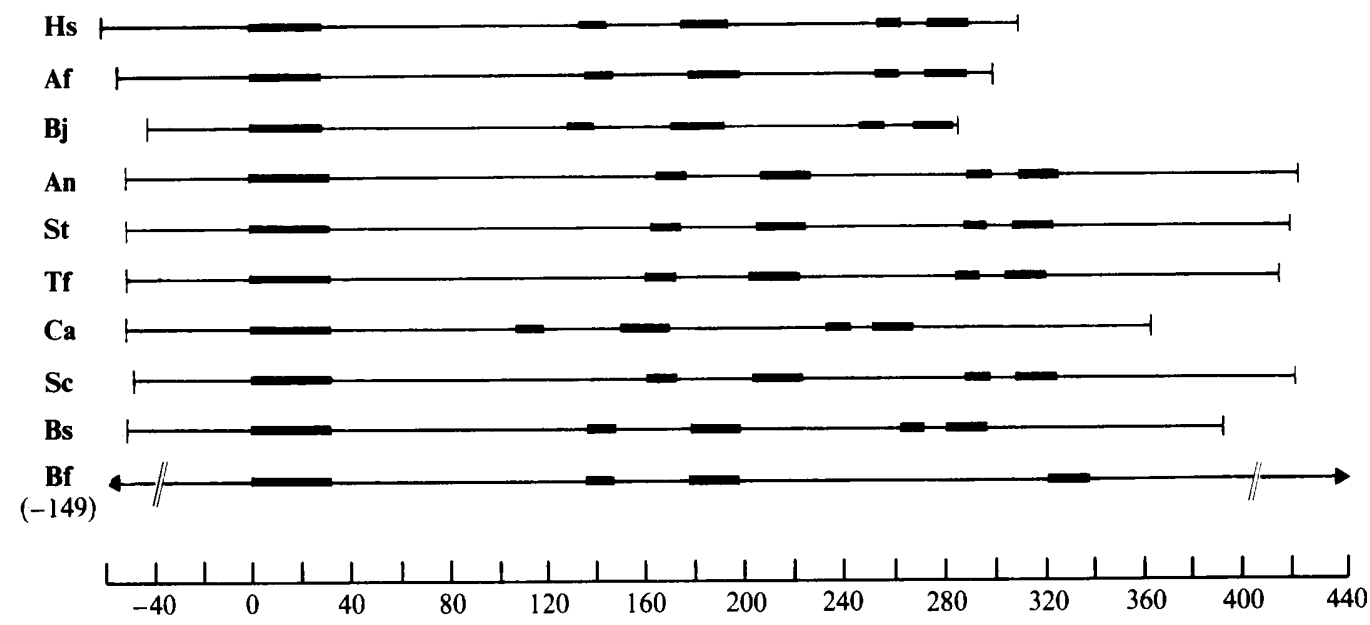

Fig. 5. Relative positions of GS regions I to V. The GS enzymes compared are the same as those in Fig. 4. Position 0 is the first amino acid residue of region $I$. The size and relative positions of regions I to $V$ and the start and end of each GS enzyme are indicated. No region IV was found in B. fragilis.

fragilis GS differs from all the other prokaryotic GSs in that the active site Trp in region I is replaced by Val, which shows no functional similarity with Trp (Fig. 4).

In the Salmonella typhimurium GS holoenzyme the Trp-58 residue is situated within $0.6 \mathrm{~nm}$ of the Tyr residue at position 398 in the carboxy-terminal portion of the adjacent subunit. Tyr-398 has been shown to be the site of adenylylation (Almassy et al., 1986; Shapiro \& Stadtman, 1968). Since the Trp-58 of one subunit is situated close to the Tyr-398 of another subunit in the $S$. typhimurium GS, it is suggested that the three-dimensional structure of this region may control the ability of an enzyme to be regulated by adenylylation. The GS enzymes which are subject to adenylylation showed strong similarity among the 18 amino acids adjacent to this Tyr residue (Janssen et al., 1988). B. fragilis GS is the first example of a GS from a Gram-negative bacterium which is not regulated by adenylylation (Southern et al., 1987). It is perhaps not surprising, therefore, that the $B$. fragilis GS does not contain either a Trp residue at the relevant position in region I, or an 18-amino-acid sequence containing a Tyr residue which even remotely resembles the $S$. typhimurium adenylylation region.

In both GSI and GSII enzymes, regions II to V are $\beta$-strands closely associated with two $\mathrm{Mn}^{2+}$ cations of one subunit (Janson et al., 1986). Region II contains four highly conserved amino acids which are not contiguous $\left[\mathrm{EV}\left(\mathrm{X}_{3-4}\right) \mathrm{Q}\left(\mathrm{X}_{1}\right) \mathrm{E}\right]$ (Fig. 4). Region III is considered to be the ATP-binding site because the sequence resembles the sequence KXXXXGXXGXGKT found in several ATP-binding proteins (Walker et al., 1982; Tischer et al., 1986). In the B. fragilis GS, region III shows the highest degree of conservation: it contains eight amino acid residues which are conserved in all the 10 eukaryote and prokaryote GS enzymes investigated, and an ATPbinding sequence can be identified (Fig. 4). Region IV is thought to be the glutamate-binding site because it is similar to the sequence DRGASIV (amino acid positions 18 to 24) of bovine and chicken glutamine dehydrogenase substrate-binding sites (Moon \& Smith, 1972; Rasched et al., 1974; Tischer et al., 1986; Rawlings et al., 1987). The $B$. fragilis GS shows no convincing similarity with the other GS enzymes in region IV. Region V, between positions 471 and 484 of the $B$. fragilis GS, shows relatively high similarity with region V of the Streptomyces coelicolor GS between positions 357 and 373 . Seven amino acids are conserved and three positions contain amino acid residues which occur in one or more other GS enzymes at the equivalent position (Glu-472, Arg-474 and Asn-481 of B. fragilis). These Glu and Arg residues are conserved in all the GS enzymes (Fig. 4).

In Fig. 5 the relative spacings of the GS regions I to V are compared. It is apparent that the relative positions of the best-conserved regions in the B. fragilis GS (regions I, II, III and V) are 
similar to the positioning of these regions in the other GS enzymes. The start of region I of the GSI subunits is located approximately 50 amino acids from the amino-terminal end, and the end of region $\mathrm{V}$ is approximately 100 amino acids from the carboxy-terminal end. In comparison, region I of the $B$. fragilis GS is preceded by 149 amino acids and there is a long carboxy-terminal region of 391 amino acids extending beyond region V. From Fig. 5 it is apparent that in all the GS enzymes the spacing between regions II and III is highly conserved and is approximately 42 amino acid residues.

\section{Conclusions}

The GS from the Gram-negative obligate anaerobe $B$. fragilis differs markedly from the GSI and GSII enzymes from other pivkaryotes amd eukaryotes. Our results demonstrate the very large size of the $B$. fragilis GS subunit, and confirm out previous suggestion that the GS is a hexamer (Southern et al., 1987). Other prokaryote GSI enzymes normally consist of 12 subunits (Streicher \& Tyler, 1980; Bhatnagar et al., 1986). The GS from Clostridium pasteurianum has been reported to consist of 20 subunits (Krishnan et al., 1986).

Classification of Bacteroides species by ribosomal RNA sequence analysis indicated that the genus Bacteroides belongs to a distinct assemblage of genera including Bacteroides, Flavobacterium and Cytophaga (Woese, 1987). The taxonomic separation of Bacteroides is supported by the structure of the $B$. fragilis GS. It will be interesting to determine whether the GS enzymes of other members of this group are similar to the GS of $B$. fragilis. If this is the case then GS enzymes with large subunits arranged as hexamers should be grouped together to form a third class of GS enzymes (GSIII). Genetic studies in Agrobacterium and Rhizobium have suggested the possible occurrence of a third GS by the cloning of a gene $g \ln T$ which complements an $E$. coli gln $A$ deletion, allowing growth in the absence of glutamine (Rossbach et al., 1988). However, no enzyme activity has yet been ascribed to the $g \ln T$ gene product.

We are grateful to D. E. Rawlings for supplying GS protein sequences and for useful discussions.

\section{REFERENCES}

Aiba, H., Adhya, S. \& de Crombrugghe, B. (1981). Evidence for two functional gal promoters in intact Escherichia coli cells. Journal of Biological Chemistry 256, 11905-11910.

Almassy, R. J., Janson, C. A., Hamlin, R., Xuong, N.-H. \& EISENBERG, D. (1986). Novel subunitsubunit interactions in the structure of glutamine synthetase. Nature, London 323, 304-309.

AMES, G. F.-L. \& NIKAIDO, K. (1985). Nitrogen regulation in Salmonella typhimurium. Identification of an $n t r C$ protein-binding site and definition of a consensus binding sequence. EMBO Journal 4, 539-547.

Bhatnagar, L., Zeikus, J. G. \& AUbERT, J.-P. (1986). Purification and characterization of glutamine synthetase from the archaebacterium Methanobacterium ivanovi. Journal of Bacteriology 165, 638-643.

Bozouklan, H. \& Elmerich, C. (1986). Nucleotide sequence of the Azospirillum brasilense Sp7 glutamine synthetase structural gene. Biochimie 68, 1181-1187.

Carlson, T. A. \& Chelm, B. K. (1986). Apparent eukaryotic origin of glutamine synthetase II from the bacterium Bradyrhizobium japonicum. Nature, London 322, 568-570.

Colombo, G. \& Villafranca, J. J. (1986). Amino acid sequence of Escherichia coli glutamine synthetase deduced from the DNA nucleotide sequence. Journal of Biological Chemistry 261, 10587-10591.

Gebhardt, C., Oliver, J. E., Forde, B. G., SaAreLAINEN, R. \& MifLIN, B. (1986). Primary structure and differential expression of glutamine synthetase genes in nodules, roots and leaves of Phaseolus vulgaris. EMBO Journal 5, 1429-1435.

GibBs, C. S., CAMPBell, K. E. \& Wilson, R. H. (1987). Sequence of a human glutamine synthetase cDNA. Nucleic Acids Research 15, 6293.

Hayward, B. E., Hussain, A., Wilson, R. H., Lyons, A., WOODCOCK, V., McINTOSH, B. \& HaRRIS, T. J. R. (1986). The cloning and nucleotide sequence of cDNA for an amplified glutamine synthetase gene from the Chinese hamster. Nucleic Acids Research 14, 999-1008.

HeNikofF, S. (1984). Unidirectional digestion with exonuclease III creates targeted breakpoints for DNA sequencing. Gene 28, 351-359.

Holdeman, L. V. \& MoORE, W. E. C. (1972). Anaerobe Laboratory Manual. Blacksburg, USA: Virginia Polytechnic Institute and State University.

IsH-HoRowicz, D. \& BURKE, J. F. (1981). Rapid and efficient cosmid cloning. Nucleic Acids Research 9, 2989-2998.

Janson, C. A., Kayne, P. S., Almassy, R. J., Grunstein, M. \& EISEnberg, D. (1986). Sequence of glutamine synthetase from Salmonella typhimurium and implications for the protein structure. Gene 46, 297-300.

Janssen, P. J., Jones, W. A., Jones, D. T. \& Woods, D. R. (1988). Molecular analysis and regulation of the $g \ln A$ gene of the Gram-positive anaerobe 
Clostridium acetobutylicum. Journal of Bacteriology 170, 400-408.

Krishnan, I. S., Singhal, R. K. \& DUA, R. D. (1986). Purification and characterization of glutamine synthetase from Clostridium pasteurianum. Biochemistry 25, 1589-1599.

MilleR, J. H. (1972). Experiments in Molecular Genetics. Cold Spring Harbor, NY: Cold Spring Harbor Laboratory.

Moon, K. \& SMITH, E. L. (1973). Sequences of bovine liver glutamate dehydrogenase. VIII. Peptides produced by specific chemical cleavages, the complete sequence of the protein. Journal of Biological Chemistry 248, 3082-3088.

Mossie, K. G., Jones, D. T., RobB, F. T. \& Woods, D. R. (1979). Characterization and mode of action of a bacteriocin produced by a Bacteroides fragilis strain. Antimicrobial Agents and Chemotherapy 16, 724-730.

Prusiner, S. \& Stadtman, E. R. (1973). The Enzymes of Glutamine Metabolism. New York: Academic Press.

Rasched, I., JoRnVall, H. \& Sund, H. (1974). Studies on glutamate dehydrogenase: identification of an amino group involved in the substrate binding. European Journal of Biochemistry 41, 603-606.

Rawlings, D. E., Jones, W. A., O’Neill, E. G. \& Woods, D. R. (1987). Nucleotide sequence of the glutamine synthetase gene and its controlling region from the acidophilic autotroph Thiobacillus ferrooxidans. Gene 53, 211-217.

Rossbach, S., Schell, J. \& DE Bruijn, F. J. (1988). Cloning and analysis of Agrobacterium tumefaciens C58 loci involved in glutamine biosynthesis: neither the $g \ln A$ (GSI) nor the $g \ln I I$ (GSII) gene plays a special role in virulence. Molecular and General Genetics 212, 38-47.

SANGer, F., Nicklen, S. \& Coulson, A. R. (1977). DNA sequencing with chain-terminating inhibitors. Proceedings of the National Academy of Sciences of the United States of America 74, 5463-5467.

ShaPIRo, B. M. \& StadTMan, E. R. (1968). 5'-Adenylyl$O$-tyrosine. The novel phosphodiester of adenylylated glutamine synthetase from Escherichia coli. Journal of Biological Chemistry 243, 3769-3771.
Shine, J. \& Dalgarno, L. (1976). Determinant of cistron specificity in bacterial ribosomes. Nature, London 254, 34-38.

Southern, J. A., Parker, J. R. \& Woods, D. R. (1986). Expression and purification of glutamine synthetase cloned from Bacteroides fragilis. Journal of General Microbiology 132, 2827-2835.

Southern, J. A., Parker, J. R. \& Woods, D. R. (1987). Novel structure, properties and inactivation of glutamine synthetase cloned from Bacteroides fragilis. Journal of General Microbiology 133, 24372446.

Strauch, M. A., Aronson, A. I., Brown, S. W., SCHREIER, H. J. \& SONENSHEIN, A. L. (1988). Sequence of the Bacillus subtilis glutamine synthetase gene region. Gene 71, 257-265.

Streicher, S. L. \& Tyler, B. (1980). Purification of glutamine synthetase from a variety of bacteria. Journal of Bacteriology 142, 69-78.

Tischer, E., Das Sarma, S. \& Goodman, H. M. (1986). Nucleotide sequence of an alfalfa glutamine synthetase gene. Molecular and General Genetics 203, 221229.

Tumer, N. E., Robinson, S. J. \& Haselkorn, R. (1983). Different promoters for the Anabaena glutamine synthetase gene during growth using molecular or fixed nitrogen. Nature, London 306, 337-342.

Walker, J. E., Saraste, M., Runwick, M. J. \& Gay, N. J. (1982). Distantly related sequences in the $\alpha+$ and $\beta$-subunits of ATP synthetase, myosin, kinases and other ATP-requiring enzymes and a common nucleotide binding fold. EMBO Journal 1,945-951.

WoEse, C. R. (1987). Bacterial evolution. Microbiological Reviews 51, 221-271.

WraY, L. V., JR \& Fisher, S. H. (1988). Cloning and nucleotide sequence of the Streptomyces coelicolor gene encoding glutamine synthetase. Gene 71, 247256.

ZabEAU, M. \& STANLEY, K. (1982). Enhanced expression of cro- $\beta$-galactoside fusion proteins under the control of the $\mathrm{P}_{\mathrm{r}}$ promoter of bacteriophage $\lambda$. EMBO Journal 1, 1217-1224. 